\title{
Forestry workers exposed to vibration: a neurological study
}

\author{
M FÄRKKILÄ,' I PYYKKÖ, ${ }^{2}$ V JÄNTTI, ${ }^{3}$ S AATOLA, ${ }^{4}$ J STARCK, ${ }^{2}$ O KORHONEN ${ }^{2}$ \\ From the Department of Neurology, ${ }^{1}$ University Hospital of Helsinki; Institute of Occupational Health, ${ }^{2}$ \\ Helsinki; Department of Neurophysiology, ${ }^{3}$ University Hospital of Tampere, Tampere; and Technical Research \\ Centre of Finland, ${ }^{4}$ Espoo, Finland
}

\begin{abstract}
Neurological findings were examined in 186 forestry workers with a mean exposure to chain saw vibration of 16.6 hours. The prevalence of active vibration induced white fingers was $5 \%$, parethaesias of the hands $53 \%$, and muscle weakness $13 \%$. Clinical polyneuropathy was observed in 16 forestry workers in the hands $(7 \cdot 5 \%)$ which did not correlate with alcohol consumption. Seventy nine forestry workers of the total population were selected for electromyographic examination. Generalised EMG based polyneuropathy in the hands was observed in only two of the 79 forestry workers $(2 \cdot 5 \%)$. The carpal tunnel syndrome was found in 20 of the 79 forestry workers $(26 \%)$. Headache and vertigo were not linked with exposure to vibration in forestry and a significant part of the numbness reported may be due to the carpal tunnel syndrome. Sensorimotor polyneuropathy is rare among forestry workers. The rise in the vibration detection thresholds was linked to the carpal tunnel syndrome.
\end{abstract}

Symptoms such as numbness, muscle weakness, and pains in the arms have been linked to peripheral nerve injuries and reported to be highly prevalent in various occupations with exposure to vibration. Numbness is the most common of these symptoms and has been reported in $40-80 \%$ of the forestry workers in Finland. Diminished muscular force has been found in about $15-30 \%$ of the forestry workers in Finland. ${ }^{12}$ Thus vibration is considered to be the reason for peripheral neuropathy but its aetiology has remained obscure.

Other symptoms have been attributed to prolonged exposure to hand arm vibration. ${ }^{23}$ The origin of these symptoms has been explained by the prolonged activation of the central autonomic system by hand arm vibration. The symptoms include vertigo, headache, insomnia, hypohidrosis or hyperhidrosis, impotence, and tremor. ${ }^{4-6}$ No conclusive evidence that the central autonomic nervous system is affected in the vibration syndrome has yet been provided. ${ }^{3}$

In electroneuromyographical studies ${ }^{78}$ different nerve entrapments have often been found among workers exposed to vibration. ${ }^{89}$ Retarded motor and sensory nerve conduction velocities have also been explained as being due to vibration induced neuropathy. ${ }^{10}$ Thus the numbness and tingling of the arms experienced by the workers have been explained

Accepted 12 January 1987 by ischaemia in the peripheral nerves, entrapment of the nerves, ${ }^{911}$ or polyneuropathy. ${ }^{1}$ Diminished deep tendon reflexes have occasionally been reported but with no clear cut connection with prolonged exposure to vibration. ${ }^{191213}$

To investigate the possible damage in the peripheral nervous system in the vibration syndrome we have studied a population of forestry workers exposed to chain saw vibration.

\section{Subjects and methods}

All forestry workers $(n=217)$ working for the same employer in the region of Suomussalmi in northern Finland were studied during a compulsory health examination. Those sawyers with less than 500 hours exposure a year were not considered professionals and were excluded. Thus a total of 186 workers were regarded as professionals. Forestry workers $(n=31)$ who had not been exposed to vibration were used as control subjects. They worked for the same employer-for example, measuring logs, storing them or acting as foremen. Table 1 shows the number and ages of the control subjects and professional forestry workers.

A history of the symptoms of the vibration syndrome was asked for as in our previous studies ${ }^{2}$ and details of alcohol consumption and expsosure to vibration were obtained. ${ }^{6}$ 
Table 1 Headache and vertigo in association with exposure to vibration

\begin{tabular}{lcl}
\hline & Forestry workers & Controls \\
\hline No of subjects & 186 & 31 \\
Age (years) & $40 \cdot 3 \pm 9 \cdot 7$ & $47 \cdot 5 \pm 8 \cdot 9$ \\
Prevalence of headache: & $29 \cdot 6 \%$ & $35 \cdot 5 \%$ \\
Neck muscle tension & $13 \%$ & \\
Migraine & $7 \%$ & \\
Others & $10 \%$ & \\
Prevalence of vertigo: & $16 \cdot 1 \%$ & $25 \cdot 8 \%$ \\
Orthostatic hypotension & $9 \%$ & \\
Vestibular origin & $2 \%$ & \\
Cervical & $4 \%$ & \\
Vascular reason & $1 \%$ & \\
\hline
\end{tabular}

All the forestry workers attended a full clinical neurological examination ${ }^{1}$ and 79 were randomly selected for electroneuromyographical (EMG) examination. In the EMG examination the motor and sensory conduction velocities of the right and the left median and ulnar nerves were determined, as well as the distal and proximal latencies. Additional measurements were carried out in the legs if neccessary.

In this study only motor nerve recordings were analysed. Vibration detection thresholds were determined at a frequency of $125 \mathrm{~Hz}$ from the distal phalanx of finger III with and without arresting the blood circulation with a sphygmomanometer manchette.

The clinical findings for the different deep tendon reflexes (patella, Achilles, brachioradialis, biceps, triceps) and sensibility (vibration detection with a tuning fork and light touch) were scored as a neuropathy index (score: $0=$ normal, $1=$ diminished, 2 = absent) for each forestry worker. The index is the sum of these seven scores.

\section{Results}

\section{CLINICAL HISTORY}

A history of vibration induced white finger (VWF) was recorded in 41 of the forestry workers $(22 \%)$. For 29 of the 186 forestry workers, however, more than two years had elapsed without a single attack of VWF and they were therefore considered to have recovered. Twelve still had attacks of VWF and therefore the prevalence of active VWF was $5 \%$. Numbness of the hands and arms was recorded in 102 workers $(55 \%)$. A history of hand muscle weakness was found in 22 workers $(12 \%)$. In our detailed analysis we found no significant correlation between the history of VWF and muscle weakness $(r=0.03, p=n s)$. The history of numbness of the hands, however, correlated significantly with the history of muscle weakness $(\mathrm{r}=0.23, \mathrm{p}<0.05)$.

Headache was reported by 55 of the 186 workers investigated. Neck muscle tension was considered to be the most common reason for headache and was present in $24(13 \%)$; migraine was found in $13(7 \%)$ and other reasons for headache in $18(10 \%)$. Vertigo was a complaint in $39(16 \%)$ of the 186 workers examined. Orthostatic hypotension was the leading cause of vertigo and found in $17(9 \%)$ (table 1). A vestibular origin of the vertigo was found in four $(2 \%)$, cervical vertigo was considered to be present in eight $(4 \%)$, and a vascular reason for vertigo in one $(1 \%)$ forestry worker. In the control group 11 of the 31 $(36 \%)$ forestry employees complained of headache and eight $(26 \%)$ of vertigo. The difference between the control group and the chain saw operators was not statistically significant.

\section{CLINICAL OBSERVATIONS}

The neuropathy index of the forestry workers was 2.0 $\pm 3 \cdot 1$ and the total exposure to chain saw vibration was $16.600 \pm 4.700$ hours. $^{6}$ The mean alcohol consumption was $3 \cdot 1 \mathrm{~kg} \pm 3 \cdot 1$ of absolute alcohol a year. We found no significant correlation either between diminished or absent reflexes and alcohol consumption $(r=0 \cdot 10, p=n s)$ or between sensory disturbances in the clinical tests and alcohol consumption $(r=0.01, p=n s)$. Furthermore, alcohol consumption did not correlate significantly with the complaint of numbness in the hands and arms $(r=0 \cdot 14, p=n s)$ or with muscle weakness $(r=0 \cdot 19, p=n s)$.

The period of exposure to vibration did not correlate significantly with diminished or absent reflexes or with sensory disturbances in the clinical tests $(r=0.03, p=n s)$ (table 2$)$. Generalised polyneuropathy was found in eight of the 186 workers (4\%). Localised neuropathy in the hands was somewhat more common and found in 14 subjects (7.5\%).

\section{VIBRATION DETECTION THRESHOLD}

Vibrotactile detection threshold evaluation of the third finger pad was carried out with and without arresting the blood circulation in 77 workers. Although a subject with VWF had somewhat higher detection threshold values (figure) no significant correlation was found between vibrotactile elevation

Table 2 Comparison of subjects selected for EMG evaluation and all professional forestry workers

\begin{tabular}{lcc}
\hline No & $\begin{array}{l}\text { EMG studied } \\
\text { forestry workers } \\
(n=79)\end{array}$ & $\begin{array}{l}\text { All professional } \\
\text { forestry workers } \\
(n=186)\end{array}$ \\
\hline $\begin{array}{c}\text { Exposure time } \\
\text { (mean } \pm \text { SD) (hours) }\end{array}$ & $\begin{array}{c}16270 \pm 4500 \\
45 \cdot 3 \pm 8 \cdot 0\end{array}$ & $\begin{array}{c}16600 \pm 4700 \\
40 \cdot 3 \pm 9 \cdot 7\end{array}$ \\
$\begin{array}{c}\text { Age (mean } \pm \text { SD) (years) } \\
\text { Alcohol consumption } \\
\text { (mean } \pm \text { SD) } \\
\text { (kg/absolute alcohol/ } \\
\text { year) }\end{array}$ & $3 \cdot 1 \pm 3 \cdot 0$ & $3 \cdot 1 \pm 3 \cdot 1$ \\
\hline
\end{tabular}




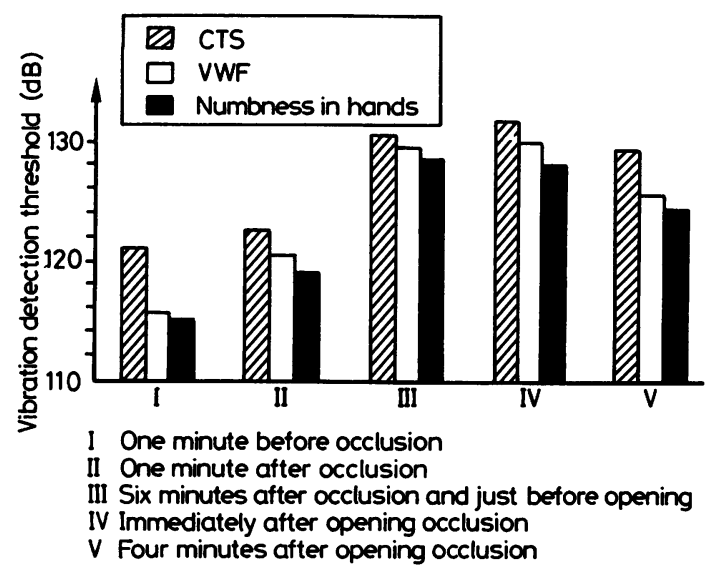

Vibrotactile adaptation during blood circulation occlusion for six minutes and four minutes thereafter for forestry workers.

Table 3 Nerve conduction results (mean and SD) of the 79 men selected for $E M G$

\begin{tabular}{lrc}
\hline & Right hand & Left hand \\
\hline Median nerve: & $52.6 \pm 3.7$ & \\
MCV (m/s) & $4.1 \pm 0.5$ & $53.7 \pm 4 \cdot 6$ \\
DL (ms) & $53.9 \pm 4.3$ & $4.2 \pm 0.6$ \\
Ulnar nerve: & $4.4 \pm 0.4$ & $55.7 \pm 4.0$ \\
MCV (m) $/ \mathrm{s})$ & $4.46 \pm 0.5$ \\
DL (ms) & & \\
\hline
\end{tabular}

and VWF. Nor did we find any correlation between a history of numbness of the hands or hand muscle weakness. The occlusion of the blood circulation and recovery did not separate the symptom groups from each other significantly in the vibration detection threshold test.

\section{ELECTRONEUROMYOGRAPHICAL EVALUATION}

Table 3 shows the mean motor conduction velocities (MCVs) and distal latencies (DLs) of the median and ulnar nerves. We found no significant correlation between alcohol consumption and MCV or DL of the median and ulnar nerves.

A history of VWF or numbness of the hands did not correlate significantly with MCV or DL values. Nevertheless, we found a significant correlation between muscle weakness and MCV $(r=0.29, p<0.05)$ and DL $(r=0.28, p<0.05)$ of the median nerve and between muscle weakness and $\mathrm{MCV}$ of the ulnar nerve $(r=0.23, p<0.5)$. A prolongation of DL in the median nerve also correlated significantly with the rise of the vibrotactile detection threshold $(r=0.22$, $\mathrm{p}<0.05$ ). In 30 subjects we found a pathologically
Table 4 Nerve conduction velocities and distal latencies (mean and SD) among men exposed to chain saw vibration

\begin{tabular}{lrr}
\hline & \multicolumn{1}{c}{$V W F$} & \multicolumn{1}{c}{$C T S$} \\
\hline Median nerve: & & \\
MCV (m/s) & $53.7 \pm 4.3$ & $53.2 \pm 4.4$ \\
DL (ms) & $4.1 \pm 0.6$ & $4.7 \pm 0.7$ \\
Ulnar nerve: & $56.8 \pm 4.1$ & $54.9 \pm 3.3$ \\
MCV (m/s) & $4.5 \pm 0.6$ & $4.6 \pm 0.5$ \\
DL (ms) & & \\
\hline
\end{tabular}

prolonged MCV or DL in the median nerve. Ten of these subjects had no symptoms or other signs of entrapment neuropathy.

\section{CARPAL TUNNEL SYNDROME}

The diagnosis of the carpal tunnel syndrome (CTS) was based on sensory and motor nerve conduction studies and Tinell's and Phalen's tests, and a typical clinical picture of CTS was found in 20 of the 79 men examined $(26 \%)$. In five of these 20 subjects the symptoms were so mild that an operation was not considered necessary. The remainder were referred for a surgical opinion and seven were operated on.

The MCVs and DLs of the median and ulnar nerve in subjects with CTS are shown in table 4. We found a significant correlation in the CTS group between a history of numbness of the hands $(r=0.38, p<0.05)$ and a history of hand muscle fatigue $(\mathrm{r}=0.47, \mathrm{p}<$ $0.05)$ and VWF $(r=0.47, p<0.05)$. Subjects with WVF also had a raised vibrotactile threshold (figure). A significant correlation was observed between the vibrotactile detection thresholds and the MCVs and DLs of the median and ulnar nerves $(p<0.01)$.

\section{Discussion}

The role of the neurological findings in the vibration syndrome has been obscure. In the present study we found a neuropathy in the hands in $7.5 \%$ of those investigated and in the feet of $4 \%$. These prevalences are the same as those reported earlier in Japan.

Other symptoms have often been observed, especially among forestry workers. ${ }^{514}$ According to field studies, these symptoms occur more frequently among subjects with VWF than among subjects without VWF. ${ }^{14}$ We found that headache was not associated with exposure to vibration since control subjects had a headache as often as the professional forestry workers. In another neurological study made in northern Finland the prevalence of headache among men of the same age was observed to be higher than that of the chain saw operators in this study. ${ }^{15}$ Thus exposure to vibration is unlikely to be the cause of the headache.

Orthostatic hypotension is a leading symptom on 
subjects with autonomic dysfunction. ${ }^{16}$ It has not often been reported in connection with vibration induced disorders although subjects may mean orthostatic hypotension when reporting vertigo. Vertigo and dizziness increase with age ${ }^{517}$ and the younger subjects with VWF seldom (in less than $10 \%$ of the cases) suffered from vertiginous attacks, whereas in the older subjects vertigo was observed in about $57 \% .{ }^{518}$ In these subjects vertigo and dizziness were not linked to VWF. Thus the prevalence of vertigo is dependent on age. In the present study we observed transient vertigo, linked to postural hypotension, among $9 \%$ of the forestry workers. This figure is rather low compared with studies conducted in some other countries. ${ }^{5}$ The definition of vertigo, the age of the population, and the questionnaire techniques may explain the relatively high prevalence of vertigo observed among forestry workers in some studies (cf ref 4) which could not be confirmed in the present study, although this population was relatively old (mean age $45 \cdot 5$ years).

In the present study we found the prevalence of polyneuropathy in the working population to be $4 \%$. Previous work from Finland reported a high prevalence $(40 \%)$ of polyneuropathy among selected workers exposed to vibration at the Institute of Occupational Health. ${ }^{13}$ This difference is presumably due to the selection of these patients for further examination rather than to the differences in the prevalence of the symptom. Thus vibration induced polyneuropathy is rare in the working population and the neuropathic findings are predominantly found in the hands. This is not typical of most polyneuropathies. ${ }^{19}$

Vibration detection threshold measurements have been proposed as a basis for making individual diagnoses. In our study they were not suitable in individual cases in the diagnosis of the vibration syndrome because of the large variation. Nevertheless, we found that in combination with the measurements of the distal latencies in EMG the enhancement of the vibrotactile detection threshold correlated with the existence of CTS among those exposed to vibration.

We also found ten subjects with EMG findings comparable with CTS without clinical symptoms. Those EMG based cases may represent patients with spontaneous recovery with residual EMG changes or vibration may also cause other types of neuropathy. Most of the unoperated cases with CTS improved spontaneously. The mechanism of the carpal tunnel entrapment is probably the swelling of the intraneural and extraneural connective tissue caused by vibration..$^{20}$ This swelling is reversible and fits the clinical and EMG data presented well and may also explain the numbness and muscle weakness in the vibration syndrome.

Our finding of a high prevalence of CTS among workers exposed to vibration confirms previous reports. Thus Lucas studied 245 workers exposed to hand-arm vibration with EMG and found signs of isolated nerve damages in the median or ulnar nerve. ${ }^{8}$ In his detailed analysis he linked the peripheral neuropathies to different entrapment phenomena in the cervical, elbow, or wrist areas. He found that the prevalence of CTS in some groups was as high as $32 \cdot 8 \%$.

In fluor miners Chatterjee $e t$ al observed in nine of the 17 workers studied $(40 \%)$ changes in the EMG that were indicative of CTS. ${ }^{7}$ Nevertheless, his data contain no clinical evaluation and it must be emphasised that a diagnosis of CTS must be based on clinical verification. Ahlborg and Voog undertook a case control study of the occurrence of CTS among workers exposed to hand-arm vibration and according to their results, heavy manual work increased the risk of CTS by a factor of two; when combined with handarm vibration the risk was increased by a factor of five. It was noteworthy that exceptionally heavy manual work with simultaneous vibration exposure could increase the risk of CTS ten times.

The present results suggest that a large part of the previously diagnosed vibration neuropathies belong to the category of CTS, which seems to be the most common entrapment neuropathy among forestry workers. A re-evaluation of the so-called vibration neuropathy should be made to determine whether the prevalence of entrapment syndromes was equally common in workers previously reported to have vibration neuropathy.

Requests for reprints to: Dr Markus Färkkilä, Department of Neurology, University Hospital of Helsinki, Haartmoninkatu 4, 00290 Helsinki, Finland.

\section{References}

1 Färkkilä M, Aatola S, Starck J, Pyykkö I, Korhonen O. Vibration induced neuropathy among forestry workers. Acta Neurol Scand 1985;71:221-5.

2 Pyykkö I, Sairanen E, Korhonen O, Färkkilä M, Hyvärinen J. A decrease in the prevalence and severity of vibration induced white fingers among lumberjacks in Finland. Scand $J$ Work Environ Health 1978;4:246-54.

3 Pyykkö I. Vibration-induced dysfunction of the autonomic nervous system: does it exist? Journal of Low Frequency Sound and Vibration 1983;1:123-8.

4 Gemne G. Vibration diseases as a central nervous disorder: development, symptomatology and pathophysiology of Soviet and Japanese classifications. In: Gemne G, Taylor W, eds. Low Frequency Noise and Vibration 1983;1:19-35. (Special issue.)

5 Futatsuka M, Takamatsu M, Sakurai T, et al. Vibration hazards in forestry workers of the chain saw operators of determined areas in Japan. Journal of Science and Labour 1980;56:221-5.

6 Harada N, Matsumoto T, Yabuki S. Subjective symptoms of vibrating tool operators in the working day. Yamaguchi Medical Journal 1980;29:433-9. (In Japanese.)

7 Chatterjee DS, Barwick DD, Petrie A. Exploratory elec- 
tromyography in the study of vibration-induced white finger in rock drillers. Br J Ind Med 1982;39:89-97.

8 Lucas E. Lesion of the peripheral nervous system due to vibration. Work Environ Health 1970;7:67-79.

9 Lucas E. Peripheral nervous system and hand arm vibration. In: Brammer AJ, Taylor W, eds. Vibration effects on the hand-arm in industry. New York: Wiley and Sons, 1982:39-43.

10 Seppäläinen AM. Peripheral neuropathy in forest workers: a field study. Work Environ Health 1972;9:106-11.

11 Ahlborgh G, Voog L. Vibration exposure and distal compression of the median nerve ("carpal tunnel syndrome"). Läkartidningen 1982;79:4905-8.

12 Harada N, Matsumoto T. Vibration disease in an iron foundry. In: Proceedings of the 9th Asian Conference on Occupational Health, Seoul 1980.

13 Juntunen J, Matikainen E, Seppäläinen AM, Laine A. Peripheral neuropathy and vibration syndrome. Int Arch Occup Environ Health 1983;52:17-24.
14 Watanabe $M$. White hand disease (local vibration disturbances). Hoppo Ringyo 1966;209:213-9. (In Japanese.)

15 Nikiforow R. Epidemiological studies on headache in northern Finland. Oulu: Acta Universitatis Ouluensis, 1981. (Academic dissertation No 69.)

16 Hines S, Houston M, Robertson D. The clinical spectrum of autonomic dysfunction. Am J Med 1981;70:1091-6.

17 Chokroverty S, Barron KD, Katz FH, Del Greco F, Sharp JT. The syndrome of primary orthostatic hypotension. Brain 1979;92:743-68.

18 Hughes RC, Cartlidge NEF, Millac P. Primary neurogenic orthostatic hypotension. J Neurol Neurosurg Psychiatry 1970;33:363-71.

19 Freemon FR. Causes of polyneuropathy. Acta Neurol Scand 1975;59(suppl):1-43.

20 Lundborg G, Dahlin LB, Hansson HA, Pyykkö I. Intraneural oedema following exposure to vibration. Scand J Work Environ Health 1987;13:326-9

.

